Original Research Paper

\title{
Performance Enhancement Strategy of Ultra-Thin CIGS Solar Cells
}

\author{
Soumaïla Ouédraogo, Boureima Traoré, Marcel Bawindsom Kébré, \\ Daouda Oubda, Adama Zongo, Issiaka Sankara and François Zougmoré \\ Département de Physique, Laboratoire de Matériaux et Environnement (LA.M.E)-UFR/SEA, \\ Université Joseph Ki-ZERBO, Ouagadougou, Burkina Faso
}

\author{
Article history \\ Received: 16-10-2020 \\ Revised: 22-12-2020 \\ Accepted: 23-12-2020 \\ Corresponding Author: \\ Soumaïla Ouédraogo \\ Département de Physique, \\ Laboratoire de Matériaux et \\ Environnement (LA.M.E)- \\ UFR/SEA, Université Joseph \\ Ki-ZERBO, Ouagadougou, \\ Burkina Faso \\ Email: ouedraogosoumaila1@gmail.com
}

\section{Introduction}

Thin-film solar cells represent a considerable hope in PV solar cells. They are studied in various laboratories to achieve the best quality/price ratio. Among thin-film solar cells, CIGS-based solar cells are popular because of their impressive performance. The efficiency of this solar cell has changed rapidly in the recent years due to the maturity of manufacturing techniques. The benefits of alkaline treatment have been mastered, resulting in a record efficiency of $23.35 \%$ (Nakamura et al., 2019). However, this industry is confronted with a serious problem that compromises its long-term sustainability. Indium and gallium, which are widely used in the manufacture of CIGS-based solar cells, are rare (Rockett, 2010). To overcome this problem, several alternatives are proposed. The replacement of indium and gallium by more abundant, inexpensive and more environment-friendly metals such as zinc and tin to form a CZTS-based solar cell. However, the best CZTS solar cells obtained from substitute metals have a record yield of $12.6 \%$ (Wang et al., 2014) far from the performance of CIGS-based cells. Reducing the thickness of the CIGS absorber layer seems to be a viable option (Chen et al., 2019). Indeed, the standard thickness of the absorber in CIGS solar cells is approximately $2.5 \mu \mathrm{m}$. If this thickness can be reduced by $50 \%$ or even below $1 \mu \mathrm{m}$, the deposition time will be considerably reduced, as well as the raw material used (Chen et al., 2019). However, reducing the thickness of the absorber is problematic. Even if the absorption coefficient of this alloy is high $\left(\approx 10^{5} \mathrm{~cm}^{-1}\right)$, a reduction in absorption and therefore the photo-current is observed when the thickness is reduced (Gouillart et al., 2019; Massiot et al., 2020).

Several laboratories around the world have embarked on this challenge with almost mitigated results. The main problem is the decrease in the solar cell performance when the thickness of the absorber is reduced.

In this study, we used SCAPS-1D software to investigate the parameters responsible for electrical losses in ultra-thin CIGS solar cells. The influence of several properties of the absorber on the electrical parameters was analyzed as a function of thickness. The optimal parameters obtained will be used to propose a new ultra-thin CIGS architecture with performances similar to those of a standard structure.

\section{Theoretical Approach}

In this numerical simulation, we used SCAPS-1D software (Niemegeers and Burgelman, 1996). By 
introducing the input parameters, SCAPS calculates the output parameters from three fundamental semiconductor equations: Poisson equation, electron and whole continuity equation. With appropriate boundary conditions, these equations are solved simultaneously to obtain at each point in the device the electronic potential, the hole quasi-Fermi level and electron quasi-Fermi level. From these state variables, the carrier concentrations, fields, currents, etc., can then be computed. The good agreement between the experimental results and those of the simulation justifies the choice of this software (Burgelman et al., 2004). The structure of the solar cell used for the simulation is shown in Fig. 1a. It consists of Soda glass/Mo/CIGS/SDL/CdS/i-ZnO/ZnO:B. The SDL layer, generally referred to as the Surface Defect Layer (SDL), is formed on the absorber surface due to the diffusion of atoms at the CdS/absorber interface. To make our model relatively simple, interface defects have been omitted voluntarily to reduce the number of parameters that change the results. To make the model reasonably realistic, bulk mid-gap defect states are introduced in each material as recombination parameters. CIGS layer absorption coefficient used in the simulation was calculated from the equation $\alpha=4 \pi k / \lambda$ and shown in Fig. 1b, where the optical constants k are extracted from references (Paulson et al., 2003) and $\lambda$ the wavelength. The absorption data used for $\mathrm{CdS}, \mathrm{i}-\mathrm{ZnO}$ and $\mathrm{ZnO}: \mathrm{B}$ layer are from experimental files introduced in SCAPS software. The temperature of the cell is set at $300 \mathrm{~K}$. The AM1.5 spectrum was used as the incident light radiation on the cell.

The parameters used for our simulation are summarized in Table 1 . These data are largely obtained from experimental and theoretical results in the literature (Gloeckler et al., 2003; Pettersson et al., 2011; Ouédraogo et al., 2014). To test the robustness of our model, the I-V characteristic obtained from the parameters of Table 1 was compared to the experimental one (Fig. 1c) from (Pettersson et al., 2011). A good agreement is achieved between the experimental and theoretical I-V characteristic data. The equivalent band diagram is shown in Fig. 1d.
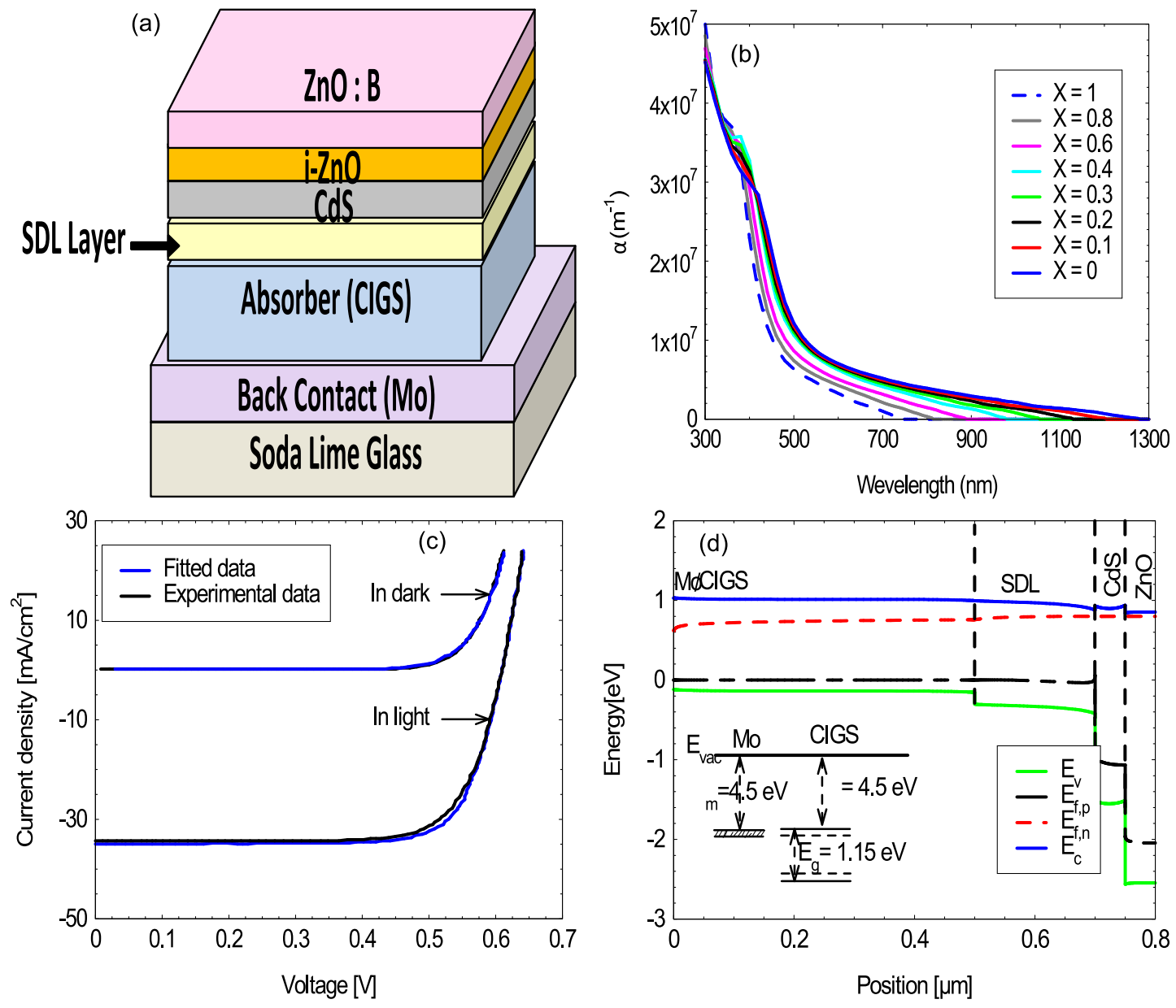

Fig. 1: (a) Solar cell structure used for simulation; (b) Absorption coefficients versus wavelength; (c) I-V characteristic compared to experimental results; (c, d) Equivalent energy band diagram of the solar cell under non-equilibrium conditions 
Table 1: The solar cells simulation parameters used in SCAPS-1D

\begin{tabular}{|c|c|c|c|c|c|}
\hline Parameters & CIGS & SDL & $\mathrm{CdS}$ & $\mathrm{i}-\mathrm{ZnO}$ & $\mathrm{ZnO}: \mathrm{B}$ \\
\hline \multicolumn{6}{|l|}{ Layer properties } \\
\hline Layer thickness (nm) & Variable & Variable & 50 & 200 & 400 \\
\hline Layer band-gap: $E_{g}(\mathrm{eV})$ & Variable & Variable & 2.4 & 3.3 & 3.3 \\
\hline Electron affinity: $\chi(\mathrm{eV})$ & Variable & Variable & 4.45 & 4.55 & 4.55 \\
\hline Dielectric relative permittivity: $\varepsilon / \varepsilon 0$ & 13.6 & 13.6 & 10 & 9 & 9 \\
\hline Conduction band effective density of states: $N_{c}\left(\mathrm{~cm}^{-3}\right)$ & $2.2 * 10^{18}$ & $2.2 * 10^{18}$ & $1.3 * 10^{18}$ & $3.1 * 10^{18}$ & $3 * 10^{18}$ \\
\hline Valence band effective density of state: $N_{v}\left(\mathrm{~cm}^{-3}\right)$ & $1.5 * 10^{19}$ & $1.5 * 10^{19}$ & $9.1 * 10^{18}$ & $1.8 * 10^{19}$ & $1.8 * 10^{19}$ \\
\hline Electron thermal velocity: $v_{e}(\mathrm{~cm} / \mathrm{s})$ & $3.9 * 10^{7}$ & $3.9 * 10^{7}$ & $3.1 * 10^{7}$ & $2.4 * 10^{7}$ & $2.4 * 10^{7}$ \\
\hline Hole thermal velocity: $v_{h}(\mathrm{~cm} / \mathrm{s})$ & $1.4 * 10^{7}$ & $1.4 * 10^{7}$ & $1.6 * 10^{7}$ & $1.3 * 10^{7}$ & $1.3 * 10^{7}$ \\
\hline Electron mobility: $\mu_{e}\left(\mathrm{~cm}^{2} / \mathrm{Vs}\right)$ & 100 & variable & 72 & 100 & 100 \\
\hline Hole mobility: $\mu_{h}\left(\mathrm{~cm}^{2} / \mathrm{Vs}\right)$ & 12.5 & 1.25 & 20 & 31 & 31 \\
\hline Doping concentration $\left(\mathrm{cm}^{-3}\right)$ & Variable & Variable & $5 * 10^{17}$ & $10^{17}$ & $10^{20}$ \\
\hline \multicolumn{6}{|l|}{ Bulk defect properties } \\
\hline Defect density and type: $N\left(\mathrm{~cm}^{-3}\right)$ & Variable (D) & Variable (D) & $5 * 10^{16}(\mathrm{~A})$ & $10^{16}(\mathrm{~A})$ & $10^{16}(\mathrm{~A})$ \\
\hline Electron capture cross section: $\sigma_{e}\left(\mathrm{~cm}^{2}\right)$ & $10^{-15}$ & $10^{-13}$ & $10^{-15}$ & $10^{-15}$ & $10^{-15}$ \\
\hline Hole capture cross section: $\sigma_{h}\left(\mathrm{~cm}^{2}\right)$ & $10^{-11}$ & $10^{-15}$ & $5 * 10^{-13}$ & $5 * 10^{-13}$ & $5 * 10^{-13}$ \\
\hline
\end{tabular}

\section{Results and Discussion}

\section{Effect of Absorber Thickness}

To reduce the absorber thickness, it is necessary to understand how the electrical parameters change as the thickness changes. In most cases, reducing the absorber thickness is accompanied by a reduction in the absorber quality (Han et al., 2012). To consider the absorber quality, three scenarios were considered. In the first (high quality), the absorber bulk defect was significantly reduced and the effective charge carrier's lifetime is 10 times greater than the traditional lifetime in CIGS solar cells (Repins et al., 2009). In the "reasonable quality" scenario, the defect density is introduced to obtain the average lifetime in CIGS solar cells. Finally, in the "poor quality" scenario, a large quantity of bulk defects has been introduced in the absorber. The effect on the electrical parameters in these 3 scenarios as function of the absorber thickness is shown in Fig. 2. As can be seen, $V_{o c}$ (Fig. 2a) and $J_{s c}$ (Fig. 2b) are more affected when the absorber thickness is reduced (ultra-thin layer less than $0.5 \mu \mathrm{m})$. This solar cell response can be attributed to a poor absorption of incident photons due to the thinning of the absorber layer and an increase in back contact recombination due to the increased proximity of the back interface for thin CIGS layers (Gouillart et al., 2019; Massiot et al., 2020). Below $0.5 \mu \mathrm{m}$, this decrease is significant and leads to low efficiency. However, the electrical performance of the device as a function of the thickness depends strongly on the absorber quality. Solar cell electrical performance is bad with high absorber bulk defect (poor quality) and ultra-thin absorbers. For high-quality absorbers, the reduction of recombination via defects leads to high performance due to the long lifetime of the photo-generated carriers.

\section{Effect of Acceptor Density and Absorber Quality}

The acceptor density in the absorber is one of the parameters that can affect the performance of solar cells
(Ruckh et al., 1996). However, doping control is recommended to optimize the performance of the device since, at high quantities, they affect the absorber's quality and therefore the lifetime of the charge carriers (Ouédraogo et al., 2013). Figure 3 shows the impact of varying hole density (equivalent to the acceptor density) on the electrical parameters of our solar cell model.

$V_{o c}$ increases significantly with the increase of the acceptor density (Fig. 3a). For acceptor density lower than $10^{14} \mathrm{~cm}^{-3}$, the absorber quality has no remarkable effect on $V_{o c}$ but leads to low values of $V_{o c}$. However, the absorber quality becomes crucial to the $V_{o c}$ when associated with high acceptor concentration.

When the acceptor density is less than $10^{14} \mathrm{~cm}^{-3}, J_{s c}$ is more dependent on the absorber quality than the acceptor concentration. This means that, for moderate doping (small values of hole density), the quality of the absorber is a crucial factor on $J_{s c}$. A high quality absorber leads to high $J_{s c}$ thanks to the reduction of absorber bulk recombination. For high acceptor concentrations $\left(>10^{14}\right.$ $\left.\mathrm{cm}^{-3}\right), J_{s c}$ decreases abruptly.

The FF (Fig. 3c) and conversion efficiency (Fig. 3d) increase with absorber doping but depend on the absorber quality. For poor quality absorbers with high hole density $\left(>10^{16} \mathrm{~cm}^{-3}\right)$, the performance of the cell is reduced. However, high conversion efficiency is achieved when a high-quality solar cell is associated with high doping $\left(>10^{16} \mathrm{~cm}^{-3}\right)$. To increase the acceptor density, many experimental works have shown the benefit of alkaline treatment during the deposition of the CIGS absorber, which reduces the conversion efficiency deficit compared to the theoretical prediction due to the increase of acceptor concentration (Nakamura et al., 2019). It appears that to obtain the beneficial effects of high acceptor density on the efficiency, it is crucial to have experimental conditions that allow the deposition of high-quality cells, which is consistent with the results obtained on the record cells (Nakamura et al., 2019). 

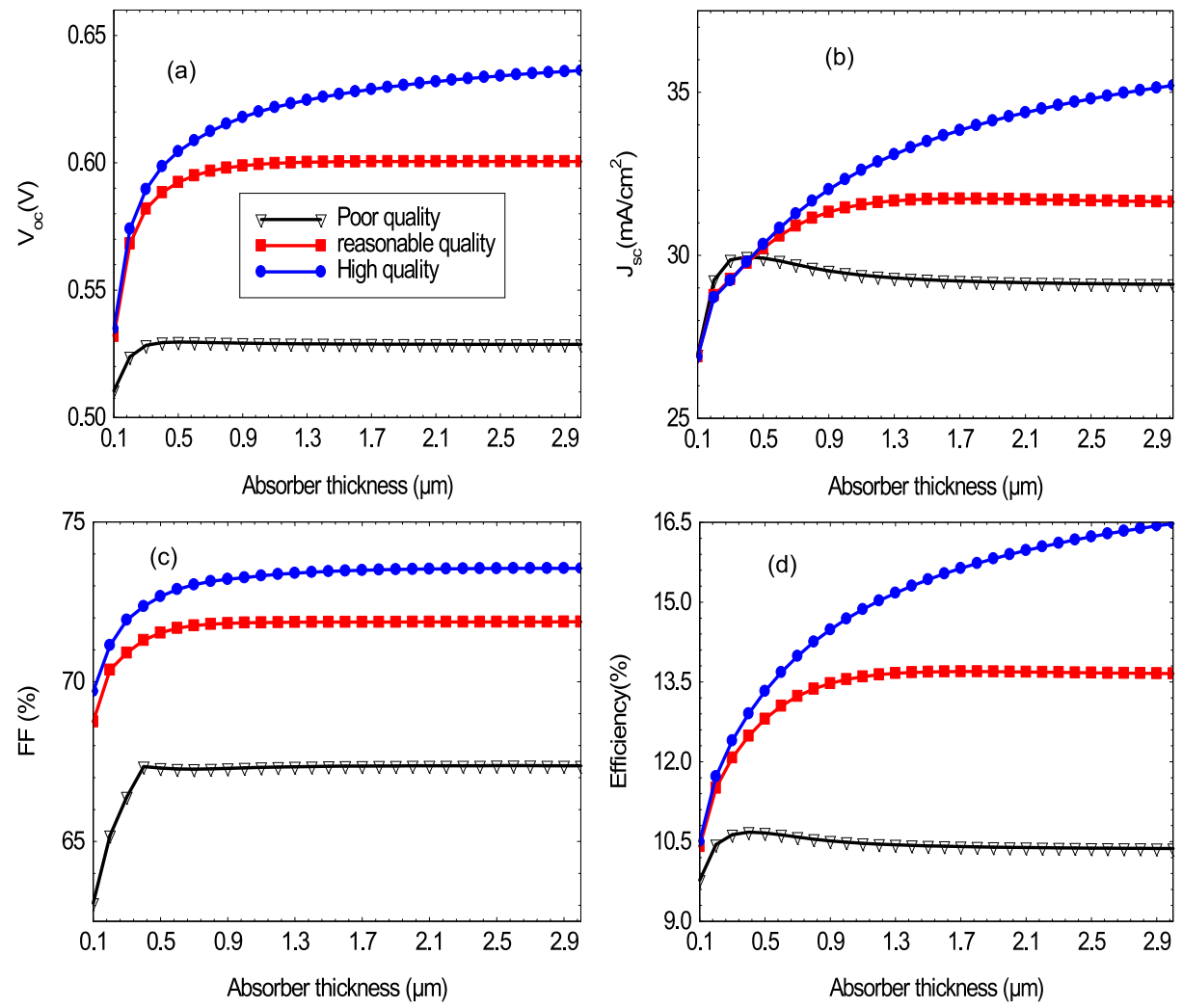

Fig. 2: Effect of absorber thickness and quality on electrical parameters: (a) $V_{o c}$, (b) $J_{s c}$, (c) FF and (d) conversion efficiency
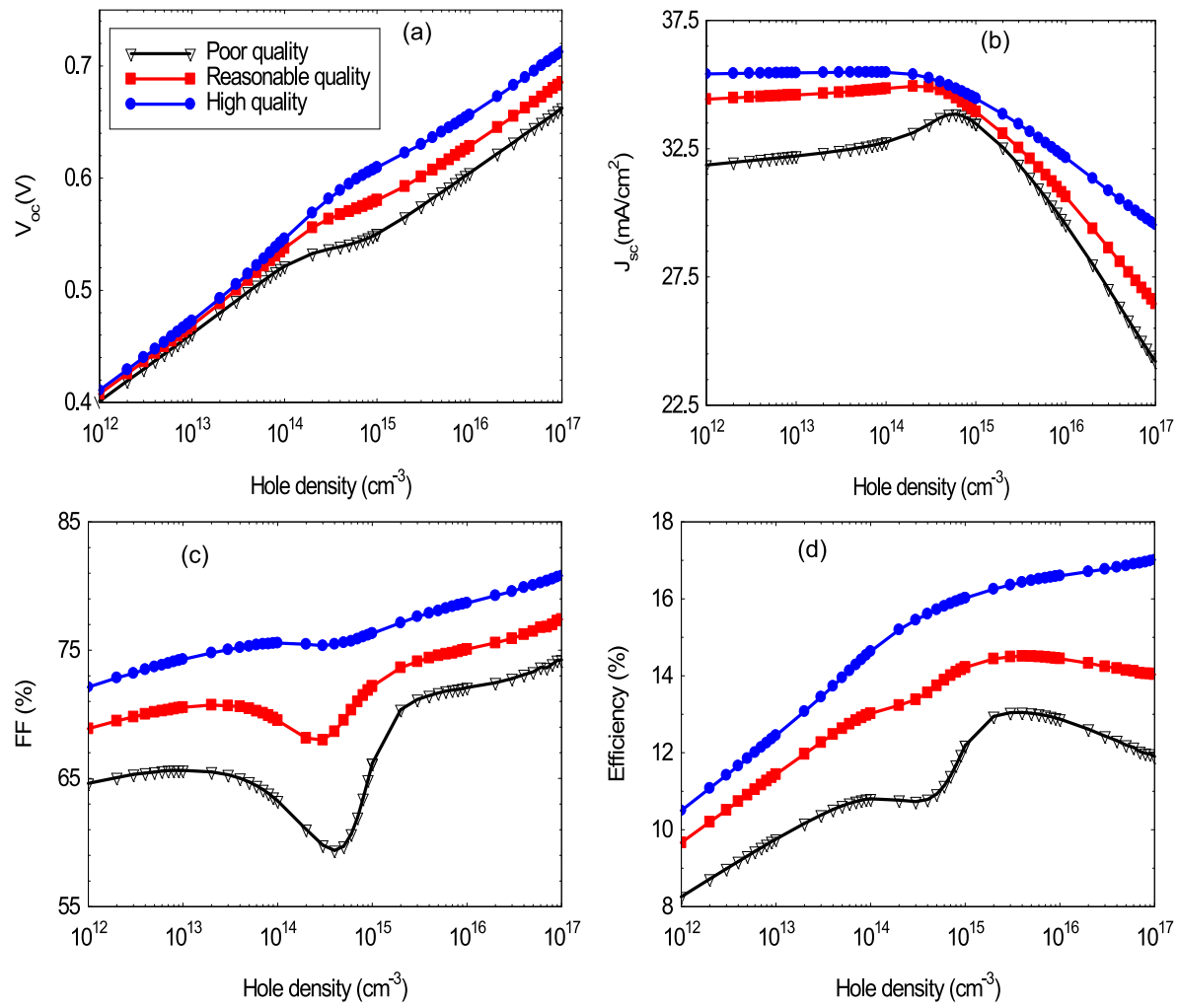

Fig. 3: Influence in the increase of hole density on the electrical parameters $\left(J_{s c}, V_{o c}, \mathrm{FF}, \eta\right)$ as a function of the absorber quality 


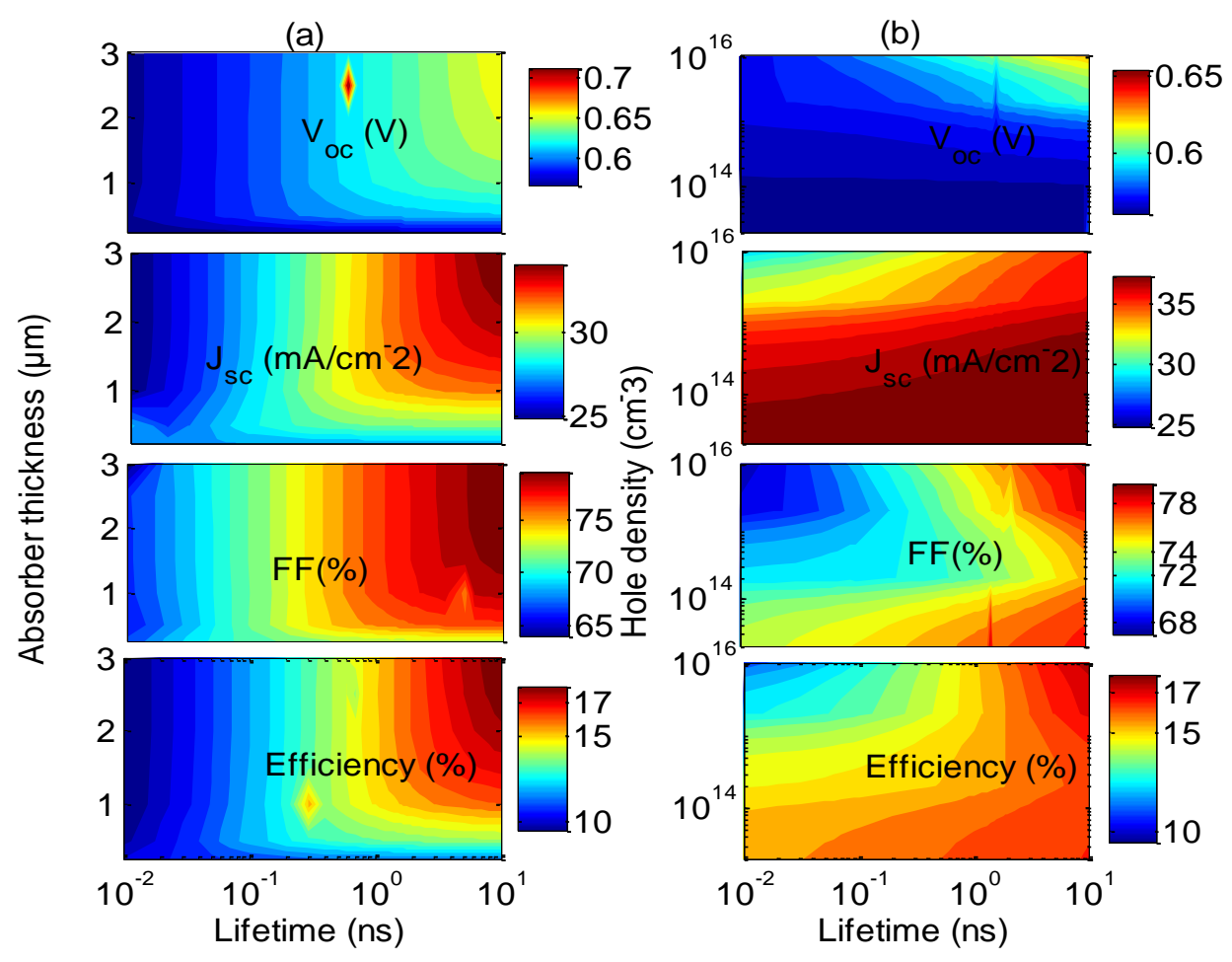

Fig. 4: Calculated impact of (a) absorber layer thickness and lifetime; (b) hole density and lifetime on the electrical parameters

The absorber quality affects the photo-generated charge carriers lifetime and therefore the performance of the cell. Figure 4 highlight how charge carriers lifetime impacts the solar cell electrical parameters when the thickness and hole concentration in the absorber are used as a variable. In Fig. 4a, the absorber thickness and carrier lifetime are varying. For short lifetimes $\left(<10^{-1} \mathrm{~ns}\right)$, the electrical parameters are negatively affected when the absorber thickness increases. Indeed, a short lifetime of photo-generated carriers will lead to an increase in recombination via defects, thus, reducing the efficiency of the solar cell. For high lifetime, the best electrical performance is obtained with absorber thickness greater than $1 \mu \mathrm{m}$. Even with high lifetimes, ultra-thin absorbers are more vulnerable to back-contact recombination, resulting in a low conversion efficiency. High conversion efficiency is achieved by combining a high lifetime (> $10 \mathrm{~ns}$ ) with a thickness greater than $1 \mu \mathrm{m}$.

Figure $4 \mathrm{~b}$ obtained by varying both hole density and carrier lifetime shows that high values of $V_{o c}$ are reached when high hole concentration is associated with high lifetime, in agreement with the results of the references (Kanevce and Gessert, 2011; Kanevce et al., 2017). Small values of $J_{s c}$ and FF are achieved at high carrier concentrations and short lifetimes. This could be explained by the fact that increasing the whole density beyond a certain value $\left(10^{14} \mathrm{~cm}^{-3}\right.$ in our study) reduces the Space-Charge Region (SCR). The quantities of photo-generated charge outside the SCR become important and must diffuse to the SCR to be collected. Combined with a short lifetime, these photo-generated carriers have a high probability to recombine before reaching the ZCR, which explains the low values of $J_{s c}$ and FF. Finally, the best conversion efficiencies are obtained at a high carrier concentration and long lifetimes.

\section{Effect of Ga-Content of the Absorber}

The gallium content in the absorber layer is an important factor to improve the performance of CIGS based solar cells. The introduction of $\mathrm{Ga}$ into the absorber layer conduct to a widening of the band-gap from 1.02 to $1.67 \mathrm{eV}$ i.e., from the gap of the CIS to CGS film (Lundberg et al., 2005). The variation of Gacontent affects also CIGS properties, such as conduction band (Lundberg et al., 2005), absorption coefficient (Alonso et al., 2002; Paulson et al., 2003), defect density (Hanna et al., 2001; Heath et al., 2002). Defect density in the absorber is highlighted as the factor limiting the performance of CIGS cells at high Ga concentrations (Hanna et al., 2001; Heath et al., 2002). Figure 5 shows the experimental and simulated Quantum Efficiency (QE) as a function of Ga-composition. The classical three-stage deposition process was used for the sample fabrication. The simulation was performed with SCAPS by computing the band-gap and electron affinity for a given value of Ga-concentration. The Defects densitys $\left(D_{d}\right)$ were adjusted to reproduce the experimental QE. As 
shown in Fig. 5, the simulated and experimental results are in excellent agreement. Moreover, the defect density decreases to a minimum when the $\mathrm{Ga}$ concentration is around 0.3 , which justifies the high efficiencies CIGS cells obtained at this Ga concentration (Huang, 2008). Beyond this concentration, the defect density increases. Inserted in Fig. 5d represents the defect density profile as a function of Ga-content with a comparison to the single-stage deposition process from reference (Hanna et al., 2001).

The defect profile as a function of Ga-content is introduced into the simulation. Figure 6 shows variations in electrical parameters when the absorber band-gap and thickness are used as variables. The quality of the absorber is also shown as a function of the band-gap range. The absorber quality affects the diffusion length and therefore the absorber thickness is an important parameter in the simulation. The open circuit voltage $\left(V_{o c}\right)$ increases with the absorber band-gap but not
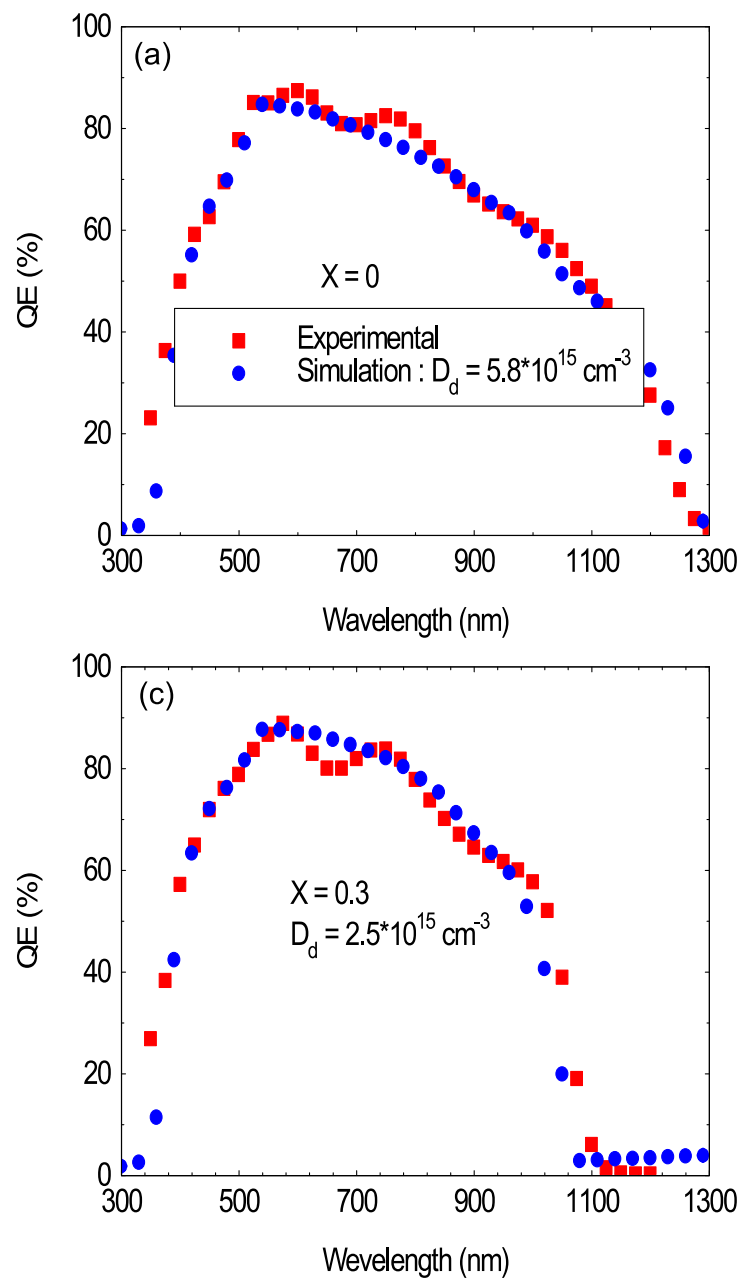

proportionally. For high Ga-content, although $E_{g}$ increases, $V_{o c}$ remains relatively constant due to the increase in recombination rate of charge carriers, especially in the space charge region. $V_{o c}$ reduction is related to the poor quality of the absorber. Nevertheless, it can be noted that the open circuit voltage is independent of the thickness of the absorber. The shortcircuit current density $\left(J_{s c}\right)$ decreases with the absorber band-gap. This decrease is especially important when the thickness of the absorber is small. This situation can be attributed to the reduction in the generation rate at the $\mathrm{p}$ $\mathrm{n}$ junction due to the decrease in absorption and the increase in recombination at the rear contact when the thickness is significantly reduced. The efficiency of the solar cell as well as the Fill Factor (FF) increase with the band-gap and the best performance is obtained for $1.15 \mathrm{eV}<E_{g}<1.35 \mathrm{eV}$, which correspond to high quality absorbers. Above this value, the overall performance of the solar cell starts to fall.
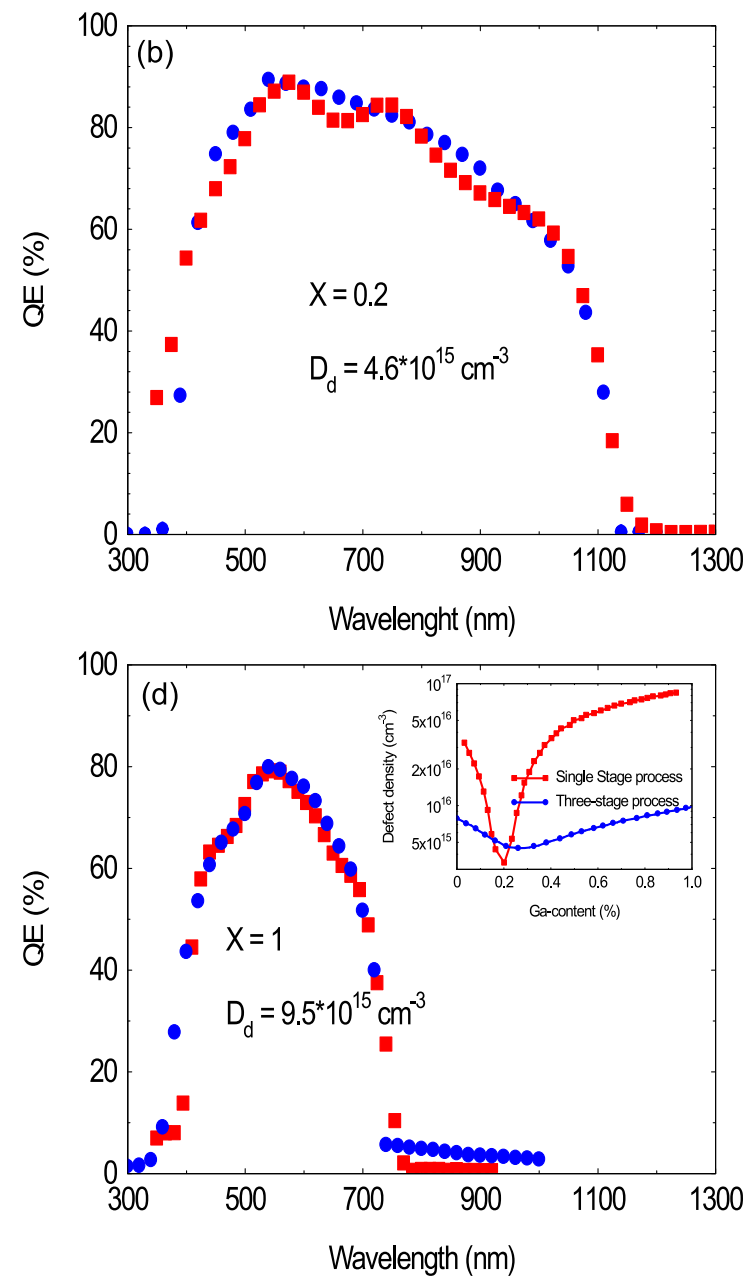

Fig. 5: Experimental quantification of Ga-content in the absorber on QE. The simulation was used to estimate defects concentration that reproduces the QE. Inserted in Fig. 5d represents the defect density profile as a function of Gacontent (Hanna et al., 2001) 

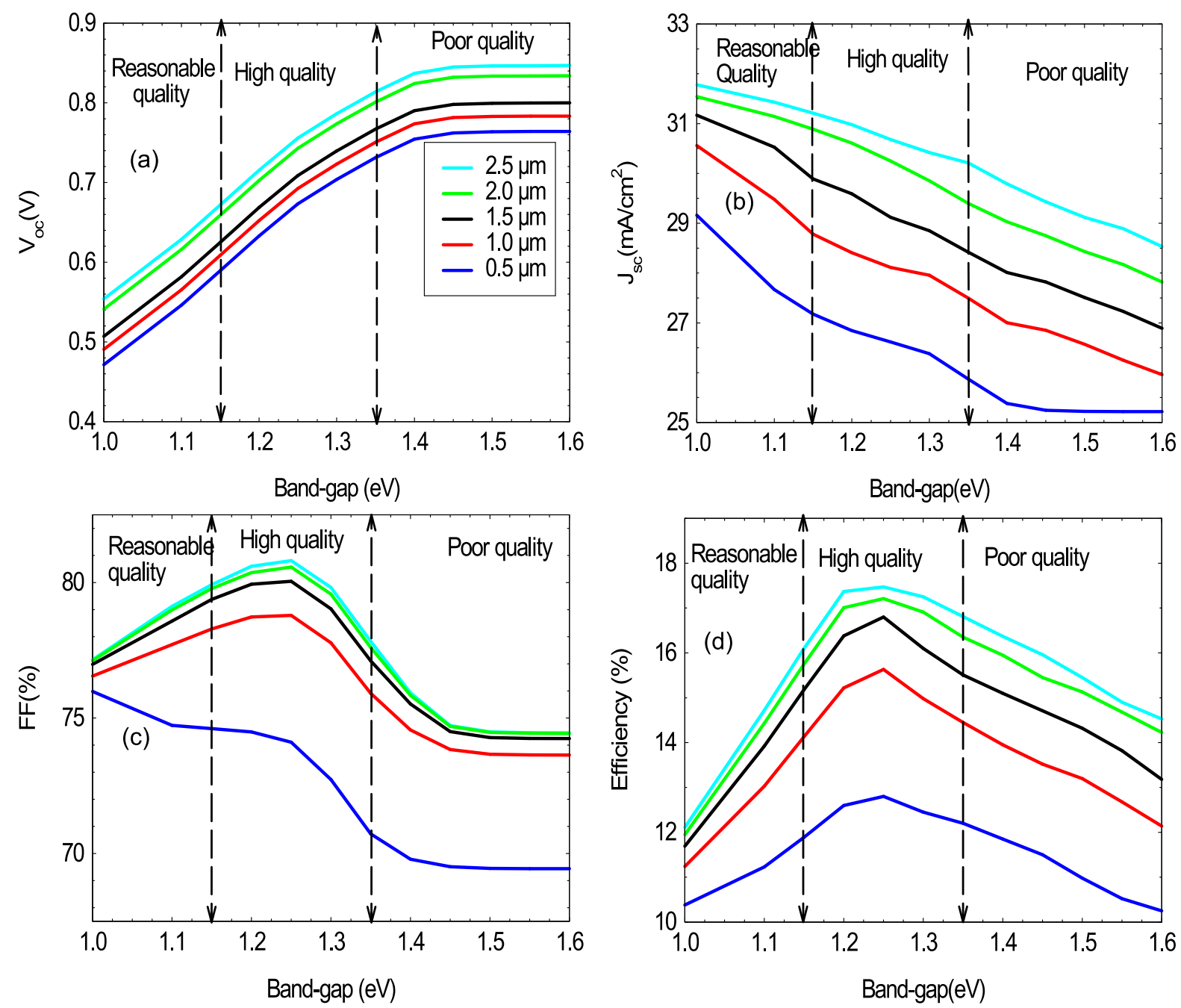

Fig. 6: Influence of absorber's band-gap and thickness on the electrical parameters $\left(J_{s c}, V_{o c}, \mathrm{FF}\right.$, Efficiency)
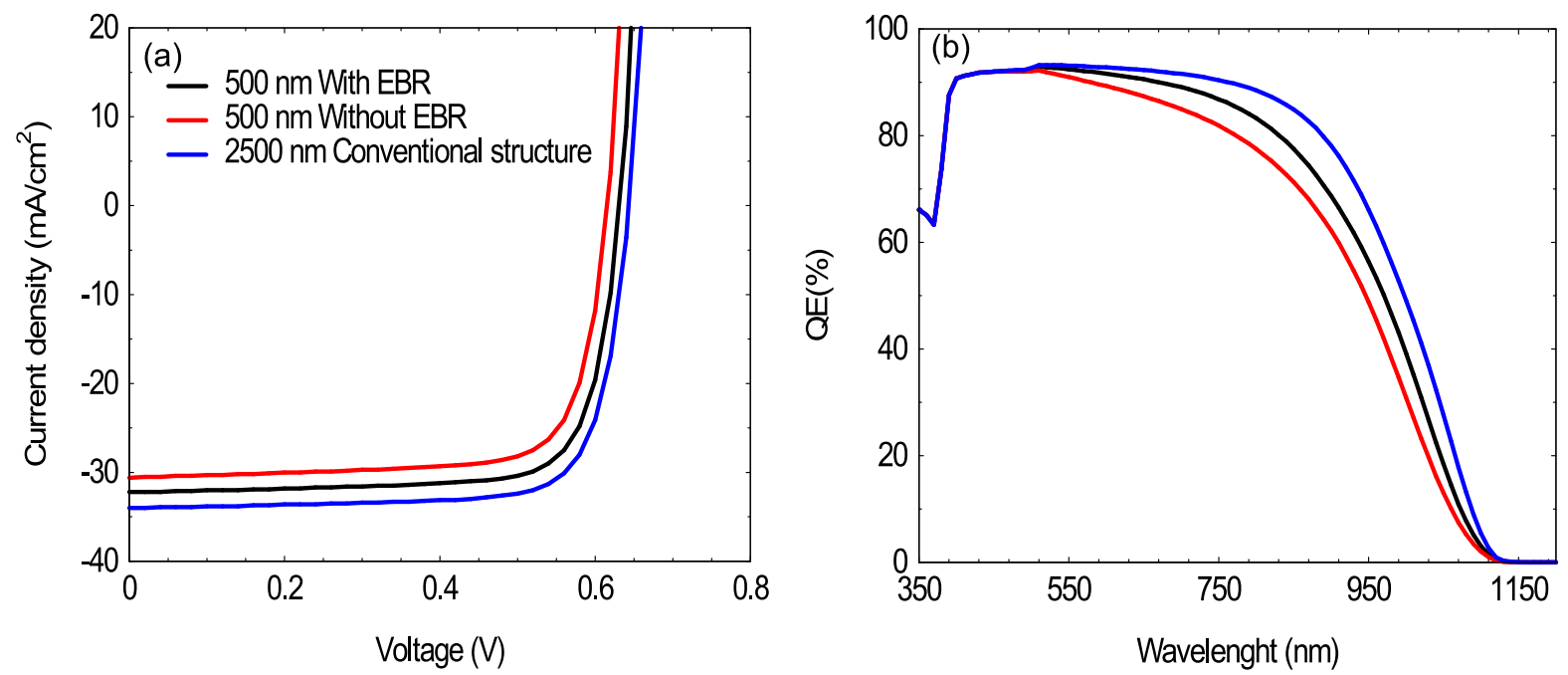

Fig. 7: (a) I-V characteristic and (b) quantum efficiency of an ultra-thin CIGS cell $(500 \mathrm{~nm})$ with and without EBR compared to the conventional structure $(2500 \mathrm{~nm})$ 


\section{Optimization of Ultra-Thin Absorbers}

The optimal absorber properties found from the previous section are used to design a high conversion solar cell. Figure 7 shows the current-voltage characteristic and the quantum efficiency of CIGS solar cells with conventional larger thickness $(2500 \mathrm{~nm})$ and greatly reduced thickness $(500 \mathrm{~nm})$. Electrical parameters for these two configurations are shown in Table 2 . When the thickness is considerably reduced compared to the conventional structure, high drop in $J_{s c}$ is observed (Table 2). The current deficit between 500 and $2500 \mathrm{~nm}$ CIGS layer is $1.75 \mathrm{~mA} / \mathrm{cm}^{2}$ as a consequence of the reduction of absorption in the long wavelengths (Fig. 7b) and the increase in recombination at the back contact.

To improve $J_{s c}$ in ultra-thin structures, one strategy is to introduce an electron reflector (commonly called EBR) at the interface between the CIGS and the Mo layers. When a thin EBR layer is introduced in $500 \mathrm{~nm}$ CIGS structure, an improvement of $J_{s c}$ and efficiency is observed (Table 2) through an improvement of the quantum efficiency (Fig. 7b).

Previous papers highlight that the important parameters for a best EBR layer are its band gap, thickness, acceptor density and electron affinity. Figure 8 shows the impact on $J_{s c}$ and efficiency when EBR layer thickness and band-gap are taken as variables (Ouédraogo et al., 2013). As can be seen in Fig. 8a, the increase in the EBR layer thickness leads to an increase in $J_{s c}$ and the conversion efficiency of the ultra-thin CIGS cell due to the reduction of recombination rate at the CIGS/Mo interface combined with increased absorption. For ultrathin absorbers, a large portion of the light passes through the absorber without being absorbed. The use of EBR layer allows the incident light to be reflected back to the absorber, increasing the electron-hole pair creation. A $J_{s c}$ of $33.2 \mathrm{~mA} / \mathrm{cm}^{2}$ and an efficiency of $16.3 \%$ are obtained when the EBR layer thickness is $1000 \mathrm{~nm}$.

Figure $8 \mathrm{~b}$ shows the impact of the EBR band-gap (varying from 1.0 to $1.5 \mathrm{eV}$ ) on $J_{s c}$ and conversion efficiency when its thickness is set to $1000 \mathrm{~nm}$.

Table 2: Electrical parameters of an ultra-thin CIGS cell $(500 \mathrm{~nm})$ with and without EBR compared to conventional structure (2500

\begin{tabular}{|c|c|c|c|c|}
\hline & $V_{o c}(\mathrm{~V})$ & $J_{s c}\left(\mathrm{~mA} / \mathrm{cm}^{2}\right)$ & FF (\%) & Efficiency $(\%)$ \\
\hline $500 \mathrm{~nm}$ without EBR & 0.6159 & 30.60 & 76.04 & 14.32 \\
\hline $500 \mathrm{~nm}$ with EBR & 0.6316 & 32.25 & 76.93 & 15.67 \\
\hline $2500 \mathrm{~nm}$ & 0.6435 & 34.00 & 77.28 & 16.91 \\
\hline
\end{tabular}

Table 3: Electrical characteristics of an ultra-thin CIGS solar cell (500 nm thickness) with an optimized EBR layer at the CIGS/Mo interface compared to a conventional structure (2500 nm thickness)

\begin{tabular}{lllll}
\hline & $V_{o c}(\mathrm{~V})$ & $J_{s c}\left(\mathrm{~mA} / \mathrm{cm}^{2}\right)$ & FF $(\%)$ & Efficiency $(\%)$ \\
\hline $500 \mathrm{~nm}$ with optimal EBR & 0.7092 & 34.60 & 77.41 & 18.99 \\
$2500 \mathrm{~nm}$ CIGS absorber & 0.6435 & 34.00 & 77.28 & 16.91 \\
\hline
\end{tabular}
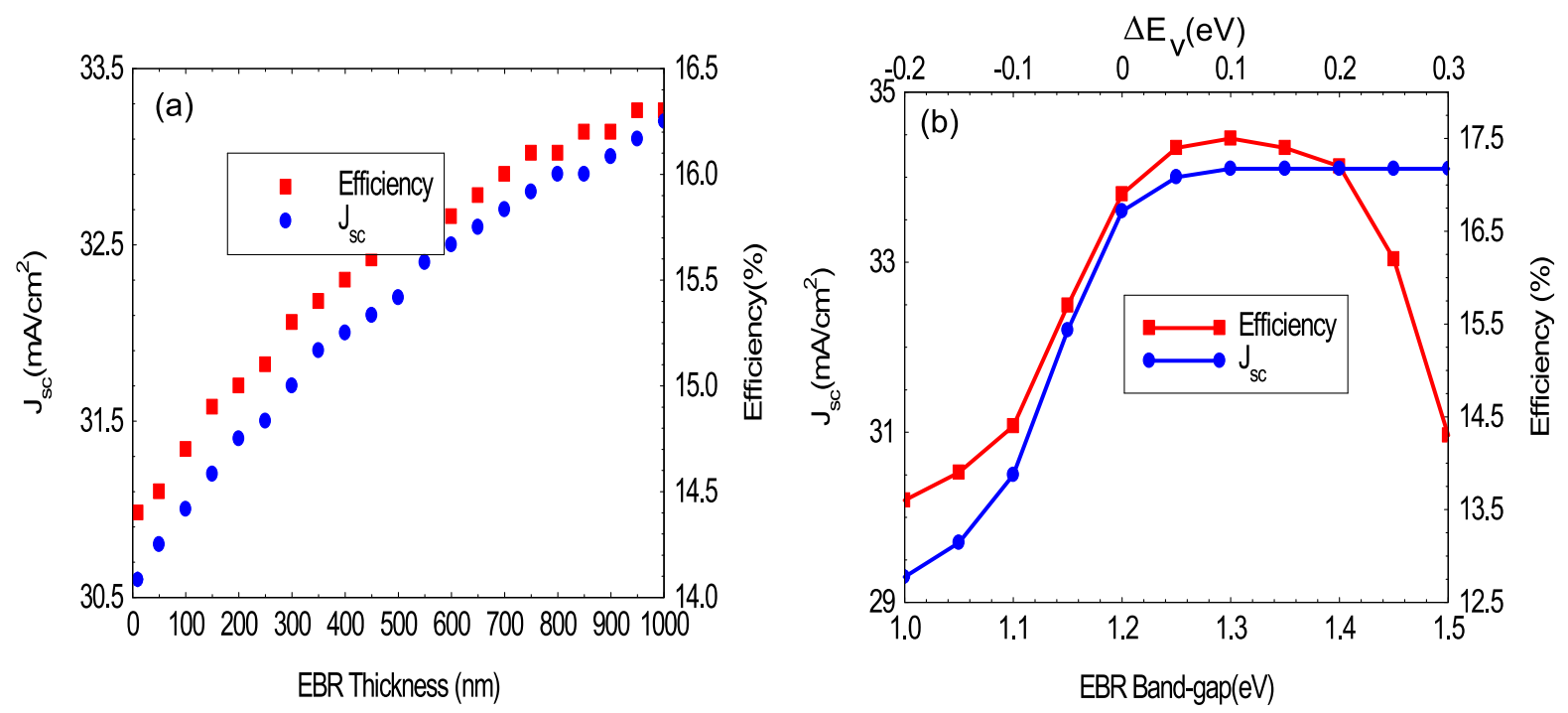

Fig. 8: Effect of EBR layer thickness (a) and band-gap (b) on $J_{s c}$ and conversion efficiency 
$J_{s c}$ increases with the EBR layer band-gap and reaches a maximum value at $1.3 \mathrm{eV}$. Above this value $J_{s c}$ seems to be insensitive to the increase in the EBR band-gap. The conversion efficiency profile is similar to $J_{s c}$ for EBR band-gaps below $1.3 \mathrm{eV}$. However, more than $1.3 \mathrm{eV}$, the increase in the EBR band-gap is harmful to the performance of the solar cell, which is consistent with the contributions of other authors (Sharbati et al., 2018) and confirms the accuracy of our model. This is due to a better alignment of the valence bands at the CIGS/EBR interface which allows a good collection of the photogenerated charges. However, above $1.3 \mathrm{eV}$, high barrier in the valence band is formed at the CIGS/EBR interface, blocking the collection of holes and leading to a drastic drop in conversion efficiency.

Table 3 shows the electrical characteristics of the ultra-thin $(500 \mathrm{~nm})$ CIGS cell when the optimal properties of the EBR layer are used in the simulation. The electrical characteristics of the classical structure (absorber thickness of $2500 \mathrm{~nm}$ without EBR) have been added for comparison. The results show that an ultra-thin (500 nm) CIGS cell with an optimized EBR layer provides high electrical characteristics compared to the thick cells. According to the EBR layer properties used in the simulation, materials such as $\mathrm{MoS}_{2}, \mathrm{AgO}, \mathrm{SnS}$, $\mathrm{Cu}_{2} \mathrm{Te}, \mathrm{CdSnP}_{2}, \mathrm{CuIn}_{5} \mathrm{~S}_{8}, \mathrm{PbCuSbS}_{3}$ can be successful EBR in ultra-thin CIGS solar cells.

\section{Conclusion}

In this study, we have explored CIGS-based solar cell and suggested pathways to improve its efficiency. The results of the simulation show that the absorber quality, band-gap, acceptor density and photogenerated charge lifetime are crucial parameters in the optimization of CIGS solar cells. After optimizing the absorber properties, a suitable strategy for producing an ultra-thin cell with comparable performance to conventional thick CIGS solar cells was proposed. The results suggest that the use of $1000 \mathrm{~nm}$ EBR layer with $1.3 \mathrm{eV}$ band-gap provides high electrical parameters and materials such as $\mathrm{MoS}_{2}, \mathrm{AgO}, \mathrm{SnS}, \mathrm{Cu}_{2} \mathrm{Te}$, $\mathrm{CdSnP}_{2}, \mathrm{CuIn}_{5} \mathrm{~S}_{8}, \mathrm{PbCuSbS}_{3}$ can be successful EBR in ultra-thin CIGS solar cells. The results obtained in this study provide a pathway to improve and design ultra-thin cells with high conversion efficiency.

\section{Acknowledgment}

The authors acknowledge the use of the SCAPS-1D program developed by Marc Burgelman and colleagues at the University of Gent in all simulations reported in this article.

\section{Authors Contributions}

Soumaila Ouédraogo, Boureima Traoré and Marcel Bawindsom Kébré: Conceptualization, methodology, software, writing-original draft preparation.

Daouda Oubda, Adama Zongo and Issiaka Sankara: Data curation, methodology, software, original draft.

François Zougmoré: Writing-reviewing and editing, supervision, validation, project administration.

\section{Ethics}

The Corresponding Author, declare that this manuscript is original, has not been published before I can confirm that the manuscript has been read and approved by all named authors.

\section{References}

Alonso, M. I., Garriga, M., Rincón, C. D., Hernández, E., \& León, M. (2002). Optical functions of chalcopyrite $\mathrm{CuGa}$ x In 1-x Se 2 alloys. Applied Physics A, 74(5), 659-664.

Burgelman, M., Verschraegen, J., Degrave, S., \& Nollet, P. (2004). Modeling thin-film PV devices. Progress in Photovoltaics: Research and Applications, 12(2-3), 143-153.

Chen, W. C., Stolt, L., \& Edoff, M. (2019, June). Ga/(Ga+ In) grading effects on ultra-thin (UT) CIGS solar cell. In 2019 IEEE 46th Photovoltaic Specialists Conference (PVSC) (Vol. 2, pp. 1-3). IEEE.

Gloeckler, M., Fahrenbruch, A. L., \& Sites, J. R. (2003, May). Numerical modeling of CIGS and CdTe solar cells: setting the baseline. In 3rd World Conference onPhotovoltaic Energy Conversion, 2003. Proceedings of (Vol. 1, pp. 491-494). IEEE.

Gouillart, L., Chen, W. C., Cattoni, A., Goffard, J., Riekehr, L., Keller, J., ... \& Collin, S. (2019). Reflective Back Contacts for Ultrathin $\mathrm{Cu}$ (In, Ga) Se 2-Based Solar Cells. IEEE Journal of Photovoltaics, 10(1), 250-254.

Han, A., Zhang, Y., Song, W., Li, B., Liu, W., \& Sun, Y. (2012). Structure, morphology and properties of thinned $\mathrm{Cu}$ (In, Ga) $\mathrm{Se} 2$ films and solar cells. Semiconductor Science and Technology, 27(3), 035022

Hanna, G., Jasenek, A., Rau, U., \& Schock, H. W. (2001). Influence of the Ga-content on the bulk defect densities of $\mathrm{Cu}$ (In, Ga) Se2. Thin Solid Films, 387(1-2), 71-73.

Heath, J. T., Cohen, J. D., Shafarman, W. N., Liao, D. X., \& Rockett, A. A. (2002). Effect of Ga content on defect states in CuIn1-xGaxSe2 photovoltaic devices. Applied Physics Letters, 80(24), 4540-4542. 
Huang, C. H. (2008). Effects of Ga content on $\mathrm{Cu}$ (In, Ga) Se2 solar cells studied by numerical modeling. Journal of Physics and Chemistry of Solids, 69(2-3), 330-334.

Kanevce, A., \& Gessert, T. A. (2011). Optimizing CdTe solar cell performance: Impact of variations in minority-carrier lifetime and carrier density profile. IEEE Journal of Photovoltaics, 1(1), 99-103.

Kanevce, A., Reese, M. O., Barnes, T. M., Jensen, S. A., \& Metzger, W. K. (2017). The roles of carrier concentration and interface, bulk and grain-boundary recombination for $25 \%$ efficient CdTe solar cells. Journal of Applied Physics, 121(21), 214506.

Lundberg, O., Edoff, M., \& Stolt, L. (2005). The effect of Ga-grading in CIGS thin film solar cells. Thin Solid Films, 480, 520-525.

Massiot, I., Cattoni, A., \& Collin, S. (2020). Progress and prospects for ultrathin solar cells. Nature Energy, 1-14.

Nakamura, M., Yamaguchi, K., Kimoto, Y., Yasaki, Y., Kato, T., \& Sugimoto, H. (2019). Cd-free Cu (In, $\mathrm{Ga})(\mathrm{Se}, \mathrm{S}) 2$ thin-film solar cell with record efficiency of $23.35 \%$. IEEE Journal of Photovoltaics, 9(6), 1863-1867.

Niemegeers, A., \& Burgelman, M. (1996, May). Numerical modelling of ac-characteristics of CdTe and CIS solar cells. In Conference Record of the Twenty Fifth IEEE Photovoltaic Specialists Conference-1996 (pp. 901-904). IEEE.

Ouédraogo, S., Zougmoré, F., \& Ndjaka, J. M. (2013). Numerical analysis of copper-indium-galliumdiselenide-based solar cells by SCAPS-1D. International Journal of Photoenergy, 2013.

Ouédraogo, S., Zougmoré, F., \& Ndjaka, J. M. B. (2014). Computational analysis of the effect of the surface defect layer (SDL) properties on $\mathrm{Cu}$ (In, Ga) Se2-based solar cell performances. Journal of Physics and Chemistry of Solids, 75(5), 688-695.
Paulson, P. D., Birkmire, R. W., \& Shafarman, W. N. (2003). Optical characterization of CuIn 1- x Ga x Se 2 alloy thin films by spectroscopic ellipsometry. Journal of Applied Physics, 94(2), 879-888.

Pettersson, J., Platzer-Björkman, C., Zimmermann, U., \& Edoff, M. (2011). Baseline model of gradedabsorber $\mathrm{Cu}$ (In, Ga) Se2 solar cells applied to cells with $\mathrm{Zn1}-\mathrm{xMgxO}$ buffer layers. Thin Solid Films, 519(21), 7476-7480.

Repins, I. L., Metzger, W. K., Perkins, C. L., Li, J. V., \& Contreras, M. A. (2009, June). Measured minoritycarrier lifetime and CIGS device performance. In 2009 34th IEEE Photovoltaic Specialists Conference (PVSC) (pp. 000978-000983). IEEE.

Rockett, A. A. (2010). The future of energyPhotovoltaics. Current Opinion in Solid State and Materials Science, 14(6), 117-122.

Ruckh, M., Schmid, D., Kaiser, M., Schäffler, R., Walter, T., \& Schock, H. W. (1996). Influence of substrates on the electrical properties of $\mathrm{Cu}$ (In, Ga) $\mathrm{Se} 2$ thin films. Solar Energy Materials and Solar Cells, 41, 335-343.

Sharbati, S., Gharibshahian, I., \& Orouji, A. A. (2018). Proposed suitable electron reflector layer materials for thin-film CuIn1- xGaxSe2 solar cells. Optical Materials, 75, 216-223.

Wang, W., Winkler, M. T., Gunawan, O., Gokmen, T., Todorov, T. K., Zhu, Y., \& Mitzi, D. B. (2014). Device characteristics of CZTSSe thin-film solar cells with $12.6 \%$ efficiency. Advanced Energy Materials, 4(7), 1301465. 